\title{
Development of the Sea Urchin Arbacia Punctulata in the Presence of the Environmental Toxin Sodium Hypochlorite
}

\author{
Meghan O. Rock ${ }^{1}$, Elizabeth C. Davis-Berg ${ }^{1}$, Brittan A. Wilson ${ }^{2}$ \\ ${ }^{1}$ Department of Science and Mathematics, Columbia College Chicago, Chicago, USA; ${ }^{2}$ Department of Biology and Chemistry, Texas \\ A\&M International University, Laredo, USA. \\ Email: edavisberg@colum.edu
}

Received July $12^{\text {th }}, 2011$; revised August 23 ${ }^{\text {rd }}, 2011$; accepted September $27^{\text {th }}, 2011$.

\begin{abstract}
Sodium hypochlorite (NaOCl) or bleach, found in effluent from wastewater treatment plants, can act as an environmental toxin. The sea urchin Arbacia punctulata is a common subject of embryological toxicity tests due to its sensitivity to environmental pollutants. Using concentrations of $\mathrm{NaOCl}$ that mimic those found in treated wastewater (0.11 ppm, $0.06 \mathrm{ppm}$, and $0.03 \mathrm{ppm}$ ) we observed minimal affects on early larval development, though most larvae took longer to develop at higher $\mathrm{NaOCl}$ concentration. There was a significant difference in the percentage of non-normal plutei based on concentration $(P=0.038)$ and significant interaction between the percent of each morphology and $\mathrm{NaOCl}$ concentration $(P=0.0027)$. The most significant change in non-normal plutei was in the retarded (shortened skeletal rods) malformation which increased in frequency with $\mathrm{NaOCl}$ concentration $(P=0.001)$. There was a significant reduction in skeletal length in both normal and retarded plutei $(P<0.05)$ as NaOCl increased.
\end{abstract}

Keywords: Arbacia, Urchin, Hypochlorite, Development, Toxin

\section{Introduction}

Sea urchins are a useful indicator species for environmental contamination due to the fact that their sperm, embryos, and larvae are very sensitive to toxins in the water [1-5]. Sea urchins also make an excellent research species because spawning and gamete collection is relatively simple, literature on echinoid embryological development is plentiful, the larvae develop quickly, animals are available year round and are easily maintained under laboratory conditions $[1,3,6]$. The sea urchin, Arbacia punctulata (Lamark, 1816), is readily available and has well documented early development stages as well as established EPA embryological toxicology methods $[1,7$, 8].

The effects of heavy metals, butylins and other environmental toxins on sea urchin embryos have been well researched. Bioaccumulation $[9,10]$, development and embryotoxicity [11-13], and more recently genotoxicity and genetic mutation [14-16] are the primary areas of concern for these toxins. These toxins can have potent effects on embryos: concentrations of $250 \mathrm{mg} \cdot \mathrm{Pb} \cdot \mathrm{l}^{-1}$ can cause accumulation of $3 \mathrm{mg} \cdot \mathrm{Pb}^{-1}{ }^{-1}$ dry weight [9].
Relatively little work has been done to determine the effects of sodium hypochlorite on sea urchin embryo development. Sodium hypochlorite $(\mathrm{NaOCl})$, (commonly found in household bleach) has wide applications in science, medicine, and especially sewage treatment, where it is used to reduce the number of viable bacteria in effluents [17]. In tests against the budding yeast, Saccharomyces cerevisiae, sodium hypochlorite causes induced genotoxic effects [18].

Human activities directly impact the ocean and in particular estuarine environments [19]. With the growing population on our coastlines, estuaries are becoming primary receiving waters for treated wastewater effluent from coastal communities. Therefore, the presence of $\mathrm{NaOCl}$ in wastewater, used in the terminal process to kill bacteria, has the potential to affect both geochemical cycles and resident organisms in the estuarine environment [20].

One previous study focused on the effects of wastewater $\mathrm{NaOCl}$ on sea urchin fertilization [20]. Even at trace amounts, $0.025-0.125 \mathrm{ppm} \mathrm{NaOCl}$, it was found that $\mathrm{NaOCl}$ negatively affected sea urchin fertilization success by reducing viability of sperm [20]. Chlorinated 
sewage, in comparison to unchlorinated sewage, was a significant and potent fertilization inhibitor though sperm showed sensitivity to either kind of sewage [20].

This study focuses on determining what, if any, developmental effects sodium hypochlorite has on Arbacia punctulata embryos and larvae. We tested the effects of sodium hypochlorite exposure at concentrations of 0.00 , $0.03,0.06$ and $0.11 \mathrm{ppm} \mathrm{NaOCl}$ on sea urchin larvae. From this we were able to determine if there were differences in the pluteus morphology (Figure 1), skeletal lengths and the ratio of normal and abnormal sea urchin larvae at each concentration.

\section{Materials and Methods}

These two experiments were performed in the spring of 2009 and repeated in spring of 2010. A pilot experiment showed that developmental timing was sensitive to low or variable laboratory temperatures causing delays (past $36 \mathrm{~h}$ ) in pluteus formation. In the work reported below, all samples were monitored for temperature throughout the experiments reported here and were maintained at $20^{\circ} \mathrm{C} \pm 2^{\circ} \mathrm{C}$.

Sodium hypochlorite solutions were prepared using Clorox bleach containing $6.15 \%$ sodium hypochlorite or $293 \mathrm{ppm}$ [21]. Solutions were prepared with artificial seawater (originally Instant Ocean) from an established cycling marine aquarium ( $36 \mathrm{ppt} \mathrm{NaCl}$ ) filtered through a Whatman Grade 1 Qualitative filter (11 microns), to reduce biologic sources of contamination. The concentrations made were $0.11 \mathrm{ppm}, 0.06 \mathrm{ppm}$, and $0.03 \mathrm{ppm}$ $\mathrm{NaOCl}$ mimicking the wastewater hypochlorite concentrations reported by Muchmore and Epel [20]. We tested

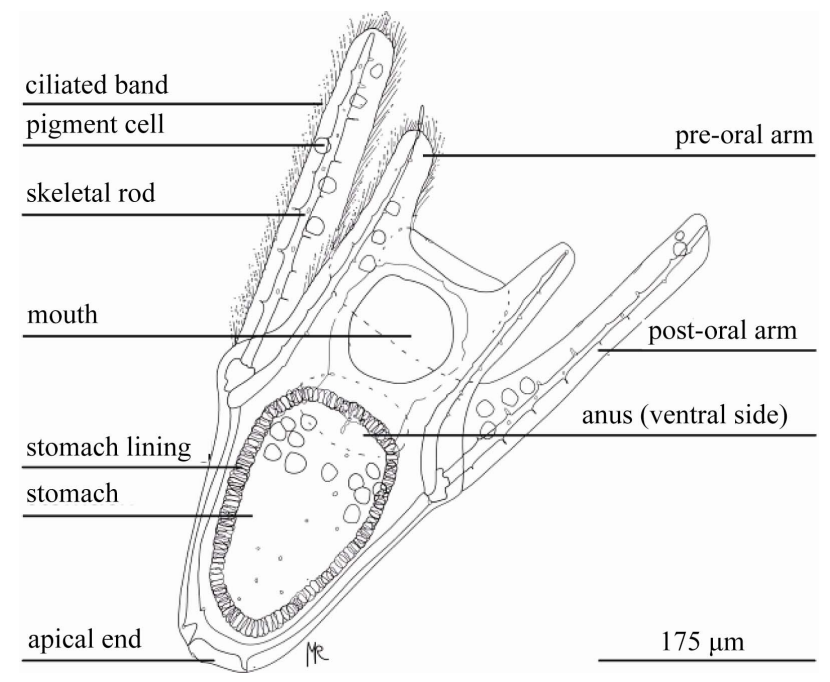

Figure 1. Major characters used to classify pluteus morphologies and length calculations. This illustration is based on a related urchin, Strongylocentrotus purpuratus, at $\sim$ five days old. these concentrations after the experiment was complete using Varian ICP-OES and found that they were accurate to $0.005 \mathrm{ppm}$.

Using standard procedure [1,7-9,20], sea urchins (ordered from Gulf Specimen Marine Lab: Panacea, FL) were spawned with a $0.5 \mathrm{ml}$ intracoelomic injection of $0.5 \mathrm{M} \mathrm{KCl}$. The eggs were collected in sea water and the sperm were stored dry in an ice bath until use. To make a standard sperm suspension, $1 \mathrm{ml}$ of sperm was added to $10 \mathrm{ml}$ of seawater. This was used to fertilize the eggs at a ratio of 2 drops of standard sperm suspension per every $10 \mathrm{ml}$ of eggs and seawater. This was repeated again after $10 \mathrm{~min}$ to ensure fertilization.

The egg/sperm mixture was kept at room temperature $\left(20^{\circ} \mathrm{C} \pm 2^{\circ} \mathrm{C}\right)$; at $40 \mathrm{~min}$ the eggs were checked for development, then were checked at 10 min intervals until first cleavage was observed in the majority of the cells in the sample ( $\leq 60 \mathrm{~min}$ ). For each replicate one $\mathrm{ml}$ of fertilized egg solution was placed in a sterile $50 \mathrm{ml}$ cell culture bottle, and then $9 \mathrm{ml}$ of the respective treated seawater were added. The final $\mathrm{NaOCl}$ concentrations were $0.11 \mathrm{ppm}, 0.06 \mathrm{ppm}$ and $0.03 \mathrm{ppm} \mathrm{NaOCl}$ respectively. The bottles were sealed with parafilm, capped lightly, and left to develop at room temperature in low light. Organisms reached the pluteus developmental stage by $45 \mathrm{~h}$ for experiment 1 and $50 \mathrm{~h}$ for experiment 2 . For each of the four concentrations of $\mathrm{NaOCl}(0.00,0.03$, 0.06 and 0.11 ), three replicates were prepared.

When the majority of larvae reached pluteus stage, samples were preserved by adding $1 \mathrm{ml}$ of $37 \%$ buffered formaldehyde to each culture bottle and then placing the samples in a $4^{\circ} \mathrm{C}$ refrigerator for $24 \mathrm{~h}$. After $24 \mathrm{~h}$ in $3 \%$ buffered formaldehyde, the samples were rinsed twice with de-ionized water to remove formaldehyde and reduce its degrading effects, then the fluid was serially replaced with ethanol in the following concentrations: $30 \%, 40 \%, 50 \%, 60 \%$ and $70 \%$. Between each ethanol rinse the samples stood $10 \mathrm{~min}$, and after the final $70 \%$ ethanol rinse the preserved larvae were stored in a $4^{\circ} \mathrm{C}$ refrigerator to slow cellular decay.

Counting was performed with a Sedgewick-Rafter counting cell on a Fisher Scientific Micromaster microscope (model CK) at 200x magnification. For each treatment, three individual $1 \mathrm{ml}$ aliquots were tallied until 400 larvae were counted. There were four counting morphological categories used: normal development $(\mathrm{N})$, reduced skeletal rod length or retarded growth $(\mathrm{R})$, malformed plutei $(\mathrm{M})$ and pre-pluteus larvae $(\mathrm{P})$ based on Kobayashi and Okamura [22]. An embryo was counted as Normal $(\mathrm{N})$ when spicule length was longer than one body length (accounting for normal larvae that were shorter) and lacking any obvious physical deformity (Figure 2(a), (f), Figure 3). An embryo was counted as 

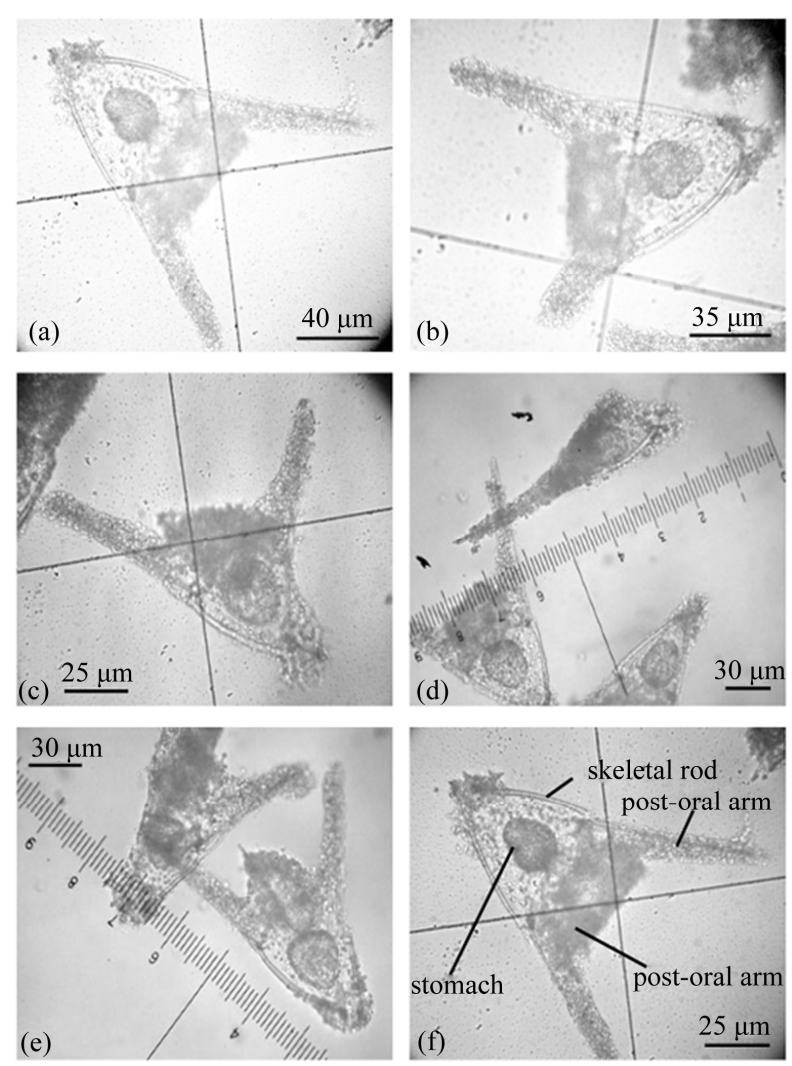

Figure 2. Different kinds of pluteus larvae seen in the experiment (from one $0.11 \mathrm{ppm} \mathrm{NaOCl}$ sample in experiment 2): (a) Normal larva; (b) Retarded larva; (c) Malformed (Toothless embryo with torsion); (d) top larva Arabesque malformation, bottom two Normal; (e) upper larva Retarded, lower larva Malformed (Toothless, slightly Vampire); f) Normal larva with labels.

retarded $(\mathrm{R})$ if the skeletal rods length was smaller than a body length (Figure 2(b), Figure 3). For a malformed (M) count, any physical deformities present were noted, and when possible, photographed (Figure 2(c)-(e)). An embryo was considered pre-pluteus $(\mathrm{P})$ when it did not have any skeletal rods or any of the internal structure expected of a larva at pluteus stage.

Measurements were taken with a marked eyepiece calibrated with a micrometer. Larvae were only measured when it was clear the whole larva was on a parallel plane to the lens and slide, so that the measurements were not distorted by foreshortening. The larva was measured along its whole length from the apical end to the end of one skeletal rod (Figure 3).

We used the program PASW Statistics (Version 17) for statistical analysis of the count and length data. Raw count data and length data were analyzed using the generalized linear model (GLM), as well as post hoc Tukey's tests. The count data was normalized using a logit function, $\ln ($ count +1$)$ (Figure 3$)$. The +1 was added in order to assess instances where there was not a specific morphology of sea urchin malformation found. The GLM used for count data was as follows: $\mathrm{NaOCl}$ was coded as a random factor, to determine if there were differences between treatments in total counts for each malformed morphology. In addition, the average percentage of each type of pluteus (normal, malformed, pre-pluteal, and retarded) was analyzed to better determine how concentration altered the presence of each type using an ANOVA followed by the post hoc Tukey's analysis. The total length of the normal and retarded plutei were analyzed using an ANOVA followed by the post hoc Tukey's analysis.

\section{Results}

Four malformed morphologies were noted during counting. The first were primarily skeletal rods with most of the cell-tissue missing, these larvae were classified as "Wishbone malformations", and were prevalent in the first experiment and seem to be related to pre-formaldehyde larvae death. The second abnormal morphology, more common in the first experiment than second, was the "Vampire malformation" (Figure 2(e)). This occurred when the two front skeletal arms of the larva lacked tissue on the spicule, making them appear as if they were fangs. The lack of tissue while a skeletal rod remains may be an indicator of larval stress. The third notable malformed morphology, and the most common in both experiments, was the "Toothless malformation" (Figure 2(c) and (e)) where an larva's smaller skeletal rods were greatly shortened or missing on one or both sides beyond what is expected due to the organism's natural asymmetry. Lastly, the "Arabesque larvae" were noted in the second experiment only; larvae had arms (usually postoral arms) that did not lie in the same plane, were bent at odd angles relative to the body and other arms, or missing altogether (Figure 2(d)). Abnormal morphologies were not counted separately, but samples with many of a single malformed morphology were noted. Some forms, especially the toothless malformation, appear similar to those found in centrifuged embryos [23] and embryos exposed to styrene derivatives [24]

We used a general linear model (GLM) to test for any significant differences between experiments; none were found. There was a significant difference in the percentage of each morphology present based on concentration $(P=0.038)$ and evidence for a significant interaction between the percent for each morphology found and $\mathrm{NaOCl}$ concentration $(P=0.0027)$. This data suggests an increase in the percent of non-normal morphology pluteus found with an increase in the concentration of sodium hypochlorite. We then compared the percent of each larval type present to determine which was contri- 

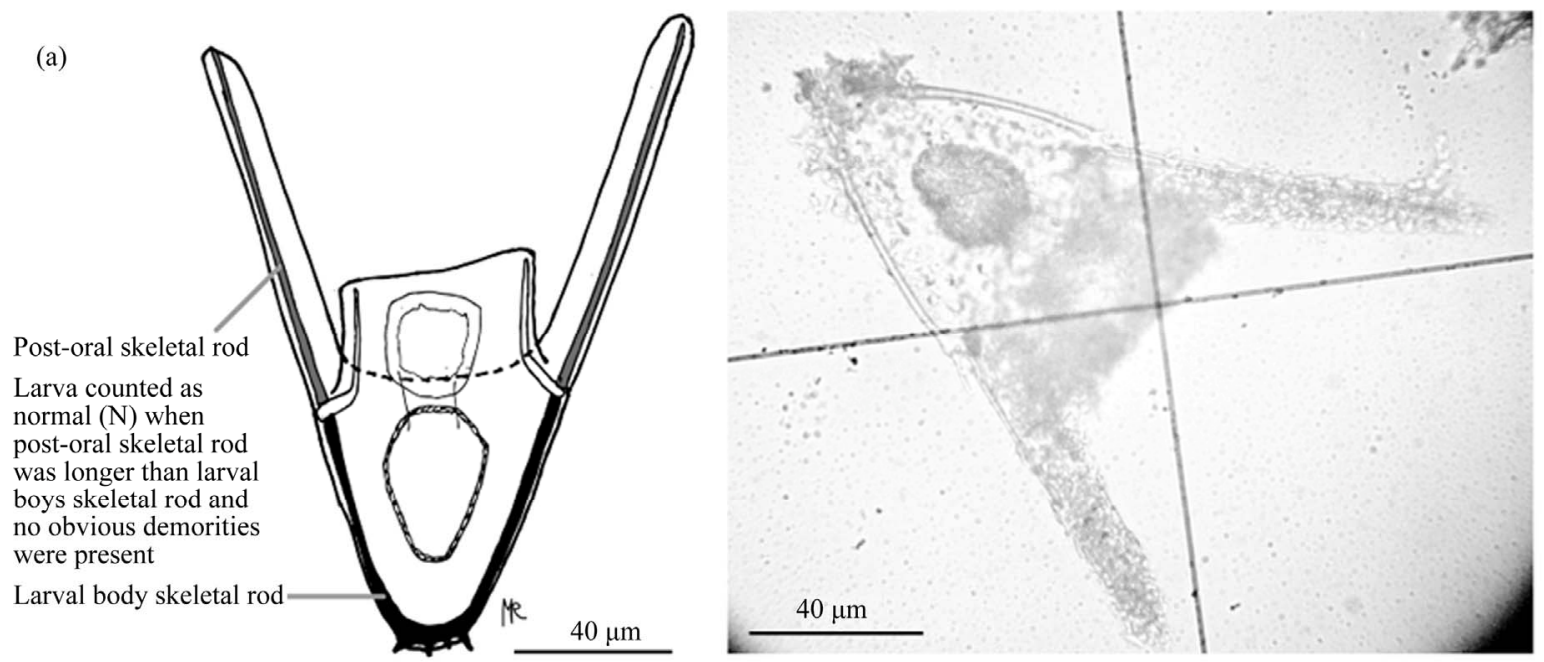

(b)
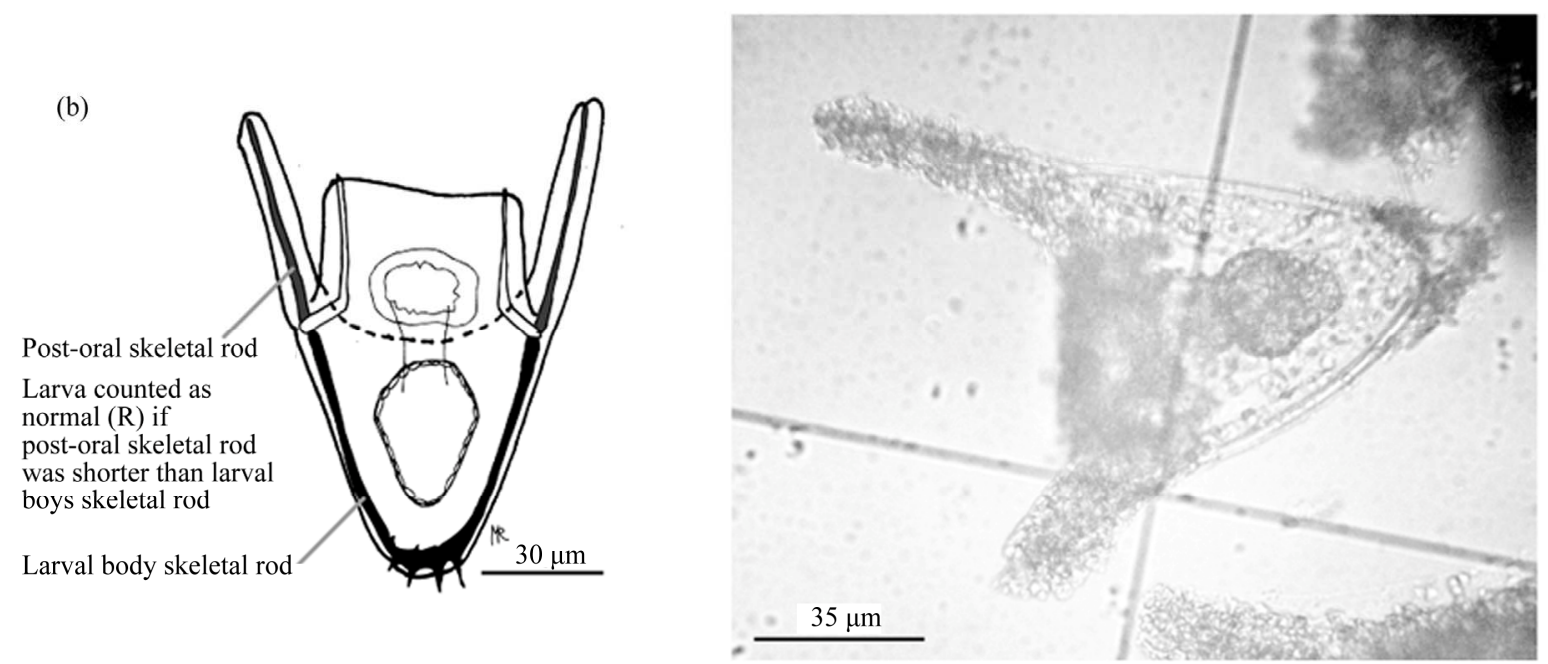

Figure 3. Larval length measurements between (a) Normal larva and (b) Retarded larva. While the total overall length is close, retarded larvae were determined via the body to arm ratio.

buting to the differences found (Figure 4). There were no significant differences in the percent of larvae that were normal, malformed or pre-pluteal due to concentration $(P>0.05)$. There was a significant increase in the number of retarded larvae with an increase in $\mathrm{NaOCl}$ concentration, both 0.06 and $0.11 \mathrm{ppm}(P<0.01)$, (Figure 4).

Given the most significant change in the pluteal morphology was found in the shortening of the skeletal rods (retarded type plutei) body length of the normal plutei and retarded plutei were assessed by concentration and type (Figure 5). Total body length is significantly shorter in retarded larvae for all treatments $(P<0.001)$. Total body length, though proportional, was significantly reduced in normal larvae at $0.11 \mathrm{ppm} \mathrm{NaOCl}(P<0.001)$. There is suggestive evidence that the body length is shorter in normal larvae in $0.06 \mathrm{ppm} \mathrm{NaOCl}(P=0.06)$. The two lower concentrations of $\mathrm{NaOCl}$ produced aver- age larval lengths $\sim 25 \mu \mathrm{m}$ longer than the average length of the larvae in the highest concentration. The increased frequency of retarded plutei resulted in the $0.03 \mathrm{ppm}$ $\mathrm{NaOCl}$ treatment having average larval lengths $\sim 30 \mu \mathrm{m}$ longer than the average larval length of the larvae in the $0.11 \mathrm{ppm} \mathrm{NaOCl}$ treatment.

\section{Discussion}

We found significant effects due to the concentration of sodium hypochlorite on both the observed larval morphologies and on the lengths of normal and retarded plutei. Count data shows that there is a significant difference between concentrations and larval morphologies.

At the highest concentrations of sodium hypochlorite solution there were more developed larvae present. However, in comparison to larvae in the lowest concentration and the control groups, these larvae had a significantly shorter total length, even in normally developed plutei. It 

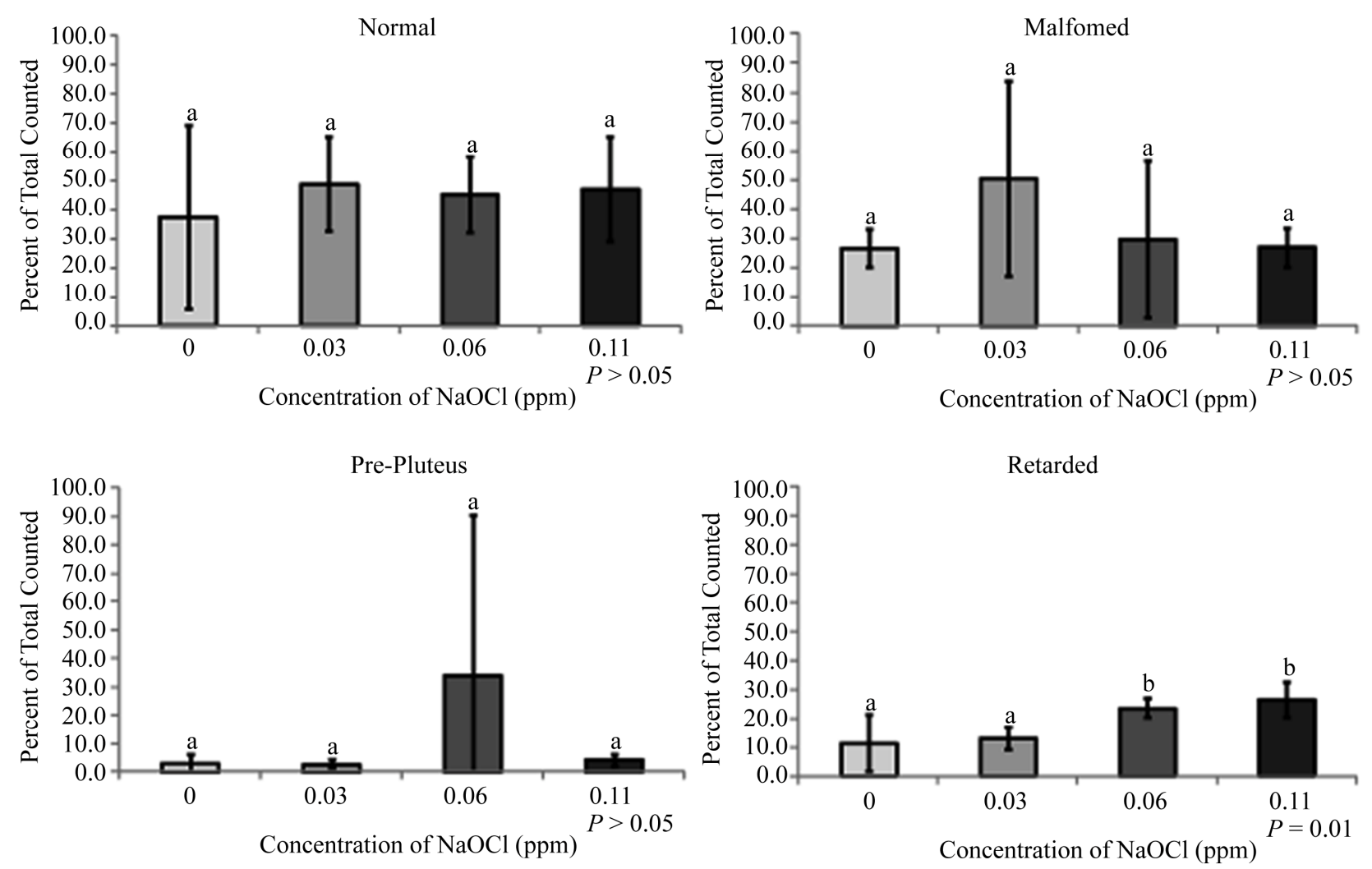

Figure 4. Differences in the average percent of each type of pluteal formation (shown with standard deviation error bars) scored for replicate counts during each of the 2 experiments; (a) normal, (b) malformed, (c) pre-pluteal, and (d) retarded. Averages were calculated by averaging the percentage of each type noted in each trial, not by combining the total counts and recalculating a pooled average.

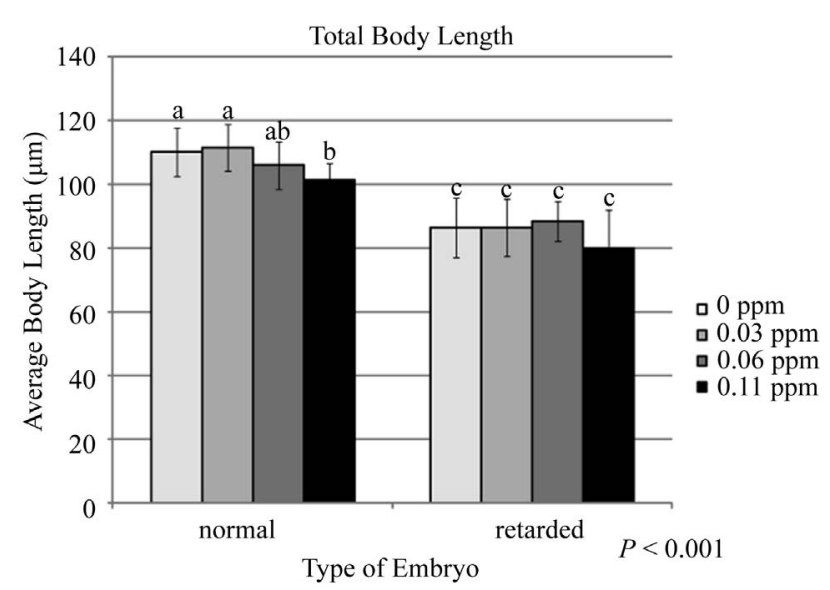

Figure 5. Pooled average larvae lengths in the Normal and Retarded categories with standard error bars. The retarded larvae are significantly shorter than normal morphology for all treatments. There is suggestive evidence that normal larvae exposed to $0.06 \mathrm{ppm}$ are shorter than controls and those exposed to $0.03 \mathrm{ppm} \mathrm{NaOCl}(P<0.06)$. Total body length, though proportional, was significantly reduced in normal larvae to $0.11 \mathrm{ppm} \mathrm{NaOCl}(P<0.001)$. This suggests that the presence of $\mathrm{NaOCl}$ may be affecting the overall growth of plutei. is possible that, while the larvae were able to develop in the $0.11 \mathrm{ppm} \mathrm{NaOCl}$, their growth was affected by the presence of sodium hypochlorite. These observations may be an indication that development can occur even in higher concentrations of $\mathrm{NaOCl}$, though Muchmore and Epel [20] reported that fertilization at these concentrations was negatively impacted.

There was also a noticeable developmental delay at room temperature $\left(16^{\circ} \mathrm{C}-20^{\circ} \mathrm{C}\right)$ for our samples. During the pilot study for this project (data not reported) a delay in development due to temperature was noted. Larvae were preserved after checking for development but because we did not scan all samples, we did not know the extent of the developmental delay. In subsequent experiments samples were checked periodically at and after the 36-h mark using the control treatment to determine if the majority of the larvae were at pluteus stage.

\section{Conclusions}

We originally hypothesized that there would be fewer developed larvae in the samples with higher levels of sodium hypochlorite and the data is inconclusive to that end, though our results show that there is a difference 
between samples by concentration levels, especially at the highest concentrations of $\mathrm{NaOCl}$. At higher levels of $\mathrm{NaOCl}$ exposure, A. punctulata larvae have shorter skeletal lengths than those larvae in lower levels of $\mathrm{NaOCl}$. The significant increase in retarded type plutei exposed to $\mathrm{NaOCl}$ and overall shortening of body length even in normal type plutei, suggests that $\mathrm{NaOCl}$ may be impacting the development of the skeletal rods. Further investigation into the physiological mechanisms behind this finding needs to be addressed. Development may be slowed by the presence of $\mathrm{NaOCl}$ as noted by the increased number of pre-pluteus larvae present in the 0.11 ppm $\mathrm{NaOCl}$ treatment. Further research is necessary to determine the impact $\mathrm{NaOCl}$ has on observed larval morphologies.

\section{Acknowledgements}

This study would not have been possible without the help of many people. Very special thanks to the Science and Math department at Columbia College Chicago for their continued financial support and encouragement throughout the course of this experiment, in particular G. Adams, B. Budy, O. Carnate, D. Jordan, M. \& R. Rock, and M. Welsh.

\section{REFERENCES}

[1] P. A. Dinnel, J. M. Link, Q. J. Stober, M. W. Letourneau and W. E. Roberts, "Comparitive Sensitivity of Sea Urchin Sperm Bioassays to Metals and Pesticides," Archive of Environmental Contamination Toxicology, Vol. 18, No. 5, 1989, pp. 748-755.doi:10.1007/BF01225012

[2] A. V. Ghiradini, A. A. Novelli, C. Losso and P. F. Ghetti, "Sea Urchin Toxicity Bioassays for Sediment Quality Assessment in the Lagoon of Venice (Italy)," Chem. and Ecol, Vol. 19, No. 2-3, 2003, pp. 99-111. doi:10.1080/0275754031000119870

[3] A.V. Ghiradini, A.A. Novelli, C. Losso and P.F. Ghetti, "Sperm Cell and Embryo Toxicity Tests Using the Sea Urchin Paracentrotus Lividus (LmK)", In: K.O. Gary, Ed., Techniques in Aquatic Toxicology, Taylor \& Francis, New York., 2005. pp. 147-168. doi:10.1201/9780203501597.ch8

[4] D. Nacci, E. Jackin and R. Walsh, "Comparative Evaluation of Three Rapid Marine Toxicity Tests: Sea Urchin Early Embryo Growth Test, Sea Urchin Sperm Cell Toxicity Test and Microtox," Environmental Toxicology and Chemistry, Vol. 5, No. 6, 1986, pp. 521-525. doi:10.1002/etc.5620050603

[5] G. Pagano, et al., "The Sea Urchin: Bioassay for the Assessment of Damage from Environmental Contaminants," In: J. Cairns Jr., Ed., Community Toxicology Testing, ASTM, Philadelphia, 1986. pp. 66-92. doi:10.1520/STP23050S

[6] R. T. Hinegardner, "Growth and Development of the Laboratory Cultured Sea Urchin," Biological Bulletin,
Vol. 137, 1969, pp. 465-475.

[7] EPA, "Purple Urchin, Strongylocentrotus Purpuratus and Sand Dollar, Dendraster Excentricus Larval Development Test Method," In: G. A. Chapman, D. L. Denton and J. M. Lazorchak, Eds., Short-Term Methods for Estimating the Chronic Toxicity of Effluents and Receiving Waters to West Coast Marine and Estuarine Organisms EPA/600/ R-95-136, U.S. Environmental Protection Agency, Cincinnati, 1995.

[8] R. T. Hinegardner, "Care and Handling of Sea Urchin Eggs, Embryos and Adults (Principally North American species)," In: G. Czihak, Ed., The Sea Urchin Embryo: Biochemistry and Morphogenesis, Springer-Verglag, New York, 1975. pp. 10-25.

[9] G. Radenac, D. Fichet and P. Miramand, "Bioaccumulation and Toxicity of Four Dissolved Metals in Paracentrotus Lividus Sea-Urchin Embryo," Marine Environmental Research, Vol. 51, No. 2, 2001, pp. 151-166. doi:10.1016/S0141-1136(00)00092-1

[10] G. Rosen, I. Rivera-Duarte, D.B. Chadwick, A. Ryan, R.C. Santore and P.R. Paquin, "Critical tissue copper residues for marine bivalve (Mytilus galloprovincialis) and echinoderm (Strongylocentrotus purpuratus) embryonic development: conceptual, regulatory and environmental implications". Marine Environmental Research, Vol. 66, 2008, pp. 327-336. doi:10.1016/j.marenvres.2008.05.006

[11] G. M. Mateyko, "Developmental Modifications in Arbacia Punctulata by Various Metabolic Substances," Biological Bulletin, Vol. 133, No. 1, 1967, pp. 184-228. doi: $10.2307 / 1539802$

[12] M. G. Marin, V. Moshino, F. Cima and C. Celli, "Embryotoxicity of Butyltin Compounds to the Sea Urchin Paracentrotus Lividus," Marine Environmental Research, Vol. 50, 2000, pp. 231-235. doi:10.1016/S0141-1136(00)00072-6

[13] J. Runnstrom, "An Analysis of the Action of Lithium of Sea Urchin Development," Biological Bulletin, Vol. 68, No. 3, 1935, pp. 378-384. doi:10.2307/1537560

[14] J. V. Goldstone, et al., "The Chemical Defensome: Environmental Sensing and Response Genes in the Strongylocentrotus Purpuratus Genome," Developmental Biology, Vol. 300, No. 1, 2006, pp. 366-384. doi:10.1016/j.ydbio.2006.08.066

[15] J. E. Hose, "Potential Uses of Sea Urchin Embryos for Identifying Toxic Chemicals: Description of a Bioassay Incorporating Cytologic, Cytogenetic and Embryologic Endpoints," Journal of Applied Toxicology, Vol. 5, No. 4, 1985, pp. 245-254. doi:10.1002/jat.2550050406

[16] M. A. Lewis, C. B. Daniels, J. C. Moore and T. Chen, "Potential Genotoxicity of Wastewater-Contaminated Pore Waters with Comparison to Sediment Toxicity and Macrobenthic Community Composition," Environmental Toxicology, Vol. 17, No. 1, 2002, pp. 63-73. doi: $10.1002 /$ tox. 10033

[17] E. Emmanuel, G. Keck, J. Blanchard, P. Vermande and Y. Perrodin, "Toxicological Effects of Disinfections Using Sodium Hypochlorite on Aquatic Organisms and Its Con- 
tributions to AOX Formation in Hospital Wastewater," Environment International, Vol. 30, 2004, pp. 891-900.

[18] A. Buschini, P. Carboni, M. Furlini, P. Poli and C. Rossi, "Sodium Hypochlorite-, Chlorine Dioxide- and Paracetic Acid-Induced Genotoxicity Detected by the Comet Assay and Saccharomyces Cervisiae D76 Tests," Mutagenesis, Vol. 19, No. 2, 2004, pp. 157-162. doi:10.1093/mutage/geh012

[19] M. J. Kennish, "Practical Handbook of Estuarine and Marine Pollution," CRC Press, New York, 1997.

[20] D. Muchmore and D. Epel, "The Effects of Chlorination of Wastewater on Fertilization in Some Marine Invertebrates," Marine Biology, Vol. 19, No. 2, 1973, pp. 93-95. doi:10.1007/BF00353579

[21] Clorox Company, "Material Safety Data Sheet for Clorox
Regular Bleach," The Clorox Company, 2005.

[22] N. Kobayashi and H. Okamura, "Effects of Heavy Metals on Sea Urchin Embryo Development: Tracing the Cause by the Effects," Chemosphere, Vol. 55, No. 10, 2004, pp. 1403-1412. doi:10.1016/j.chemosphere.2003.11.052

[23] T. K. Naidenko, E. N. Gakhova, V. P. Naidenko and B. N. Veprintsev, "Evaluation of the Viability of Sea Urchin Larvae after Cryopreservation of Embryos," In: T. Yanagisawa, et al., Eds., Biology of the Echinodermata, Balkema, Rotterdam, 1990.

[24] G. Pagano, A. Esposito, G. G. Giordano and H. B. E., "Embryotoxic and Teratogenic Effects of Styrene Derivatives on Sea Urchin Development," Scandinavian Journal of Work, Environment \& Health, Vol. 4, Suppl. 2, 1978, pp. 136-141. 